\title{
The Effect of Teaching Family Medicine Clerkship Students on Preceptor Productivity
}

Tomoko Sairenji, MD, MS I Samuel Griffin, MPA | Misbah Keen, MD, MBI, MPH

PRiMER. 2020;4:8.

Published: 5/12/2020 | DOI: 10.22454/PRiMER.2020.550339

\section{Abstract}

Introduction: High-quality, experiential learning in outpatient settings is indispensable for medical student education; however these settings are difficult to recruit and retain. The majority of primary care physicians are employed by organizations and are under pressure to increase their relative value unit (RVU) production. Although the common perception that teaching medical students decreases productivity is unproven, it is likely a barrier for primary care physicians pursuing clinical teaching. We sought to investigate whether medical student teaching affects clinical productivity.

Methods: We recruited 15 family medicine (FM) clerkship sites to participate in our study via email and at an in-person meeting. For each preceptor, we collected billing data in the form of current procedural terminology (CPT) codes for all patient encounters and the number of patients seen per half-day for when the preceptor had a student and when they did not. We converted CPT codes to RVU data. We compared differences in productivity for each individual preceptor, and we used a paired $t$ test to examine collective data with and without a student.

Results: Ten preceptors at six FM clerkship sites provided reliable data. The average RVU per half-day without a student was 10.84 , and it was slightly higher at 11.25 when a student was present $(P=.74)$. The average number of patients seen per half-day without a student was 8.32 and it was slightly lower at 7.87 when a student was present $(P=.58)$.

Conclusion: This study shows promising data that teaching students in the outpatient setting does not decrease preceptor productivity. This pilot study can lead to a larger-scale exploration of family medicine preceptor productivity in different settings and institutions.

\section{Introduction}

High-quality educational experiences in the outpatient setting are indispensable for medical students to learn critical aspects of primary care, and many medical and other health profession schools rely heavily on community primary care physicians to provide these learning opportunities. The majority of primary care physicians are currently employed by hospitals or large organizations and are under pressure to increase their relative value units (RVU) production, to provide better quality care, and achieve higher patient satisfaction. ${ }^{1,2}$ Thus, it is a reality that recruitment and retention of teaching sites has become difficult for medical schools. ${ }^{3}$ Though the notion that teaching students negatively affects productivity is not proven, ${ }^{4}$ many primary care physicians perceive this to be true. ${ }^{5,6}$ This may be a barrier for physicians to teach students in the outpatient setting. ${ }^{7}$

The objective of this study was to examine how students in the clinic impact preceptor productivity. Evans et al 
recently found no difference in RVU production of preceptors with or without a physician assistant student. ${ }^{8}$ To our knowledge, our pilot study is the first conducted in a family medicine setting with medical students since $1994 .{ }^{4}$ Identifying whether productivity is affected by teaching students may help inform a preceptor's decision to teach. Additionally, medical schools that rely heavily on clinic preceptors may become more sensitive to how their students impact community preceptors through this study.

\section{Methods}

This was a quantitative study of productivity in the outpatient clinic settings at the University of Washington School of Medicine family medicine clerkship sites. We recruited 15 sites to participate via email and at an in-person meeting. Clerkship sites did not include residency sites, and sites where medical students worked with fewer (three or fewer) preceptors during their rotation were chosen to ensure better productivity data comparisons with and without a student.

Billing data in the form of current procedural terminology (CPT) codes for all patient encounters and the number of patients seen were reported by each preceptor on a billing data form for each half-day (see Appendix). Forms asked for patient age, sex, and level of student involvement for each case. Forms were collected for two timeframes during the 6-week rotation: 2 weeks with a medical student and 1 week without a student during a timeframe proximal to the student rotation between March and October of 2016. We collected 2 weeks of data with a student because of potential variability based on the timing of data collection within the 6-week rotation; productivity could be affected by whether the student was in the first few weeks or last few weeks of their clerkship. Forms were collected by the primary investigator by email attachment or fax. We converted CPT codes to RVUs using the 2017 CMS National Physician Fee Schedule. We examined differences in individual preceptor productivity and conducted a paired $t$ test (SPSS) to examine collective differences with and without a student.

In cases where CPT codes did not correlate directly to an RVU, we used proxies; in 21 OB visits, a 1.09 RVU was given based on ([global delivery 32.16] - [delivery + postpartum visit 18.01]) divided by the general average of 13 visits per prenatal course; 24 visits were documented as "no billing codes" and given a CPT code of 99213; two preventative visits with no age listed were given a 1.5 RVU, which is the lowest RVU that can be assigned for a preventative visit. There were invalid CPT codes remaining for nine visits after these adjustments were made. Those visits were given zero RVUs.

We obtained written consent from participating preceptors after an in-person orientation and an email outlining the study. This study was reviewed and approved by the University of Washington Human Services Division (HSD No.51297_EA), the IRB equivalent at our institution.

\section{Results}

Eleven preceptors from seven independent FM clerkship sites participated in this study. One preceptor data set was eliminated as data were incomplete; we used data from 10 preceptors from six sites for analysis (Table 1).

Cumulatively, 193 half-day clinic sessions were captured; 65 sessions without students, 128 sessions with students, and 1,657 patient encounters; we accounted for 544 on days without students and 1,113 on days with students.

The average RVU per half-day without a student was 10.84 and it was slightly higher at 11.25 when a student was present. The difference was not statistically significant with a $P$ value of .74 . The average number of patients seen per half-day without a student was 8.32 and it was slightly lower at 7.87 when a student was present. The difference was not statistically significant with a $P$ value of .58 (Table 2 ).

\section{Conclusions}

There was no statistically significant difference in clinical productivity, as defined by billing data and the number of patients seen per half-day session when there was a student working with a preceptor and when there was no 
student. Because the push for increased clinical productivity is a stressor for many primary care practices, this information may help recruit and retain preceptors in the outpatient setting. Knowing that there is no productivity loss may be helpful for practice administrators to be supportive of physicians or other practitioners of teaching students.

Study limitations include a small sample size and that it is limited to one medical school, though it did include sampling from six independent clerkship sites. Only seven of 15 eligible sites decided to participate, likely due to increased work burden on the preceptor to collect data. There was imperfect data collection where preceptors did not contribute data for the full duration requested, and proxy coding was used in $47(2.8 \%)$ of total encounters that could have altered the accuracy of our results. Additionally, this study did not explore the preceptor experience. There may be a sense of productivity loss due to extra time spent in clinic or the need to complete work at home when working with a student. Merely demonstrating that RVU billing and patient numbers are not affected by students in clinic is likely not enough for preceptors to decide to teach. It is also important to explore how else students might affect a typical work day for a preceptor and their overall satisfaction. For the future, larger-scale studies could be conducted across institutions and sites, and include other metrics of experienced productivity, such as extra time spent on documentation and administration per clinic session.

\section{Tables and Figures}

Table 1: Site Information and Individual Preceptor Data

\begin{tabular}{|c|c|c|c|c|c|c|c|c|c|}
\hline \multirow[b]{2}{*}{ Site } & \multicolumn{3}{|c|}{ Site Information } & \multicolumn{6}{|c|}{ Preceptor Data } \\
\hline & $\begin{array}{c}\text { No. } \\
\text { Providers } \\
\text { at Site }\end{array}$ & $\begin{array}{l}\text { No. } \\
\text { Exam } \\
\text { Rooms } \\
\text { at Site }\end{array}$ & Setting & Preceptor & $\begin{array}{l}\text { No. Half } \\
\text { Days: } \\
\text { Student } \\
\text { (S) }\end{array}$ & $\begin{array}{l}\text { No. Half } \\
\text { Days: No } \\
\text { Student } \\
\text { (NS) }\end{array}$ & $\begin{array}{l}\text { Average } \\
\text { RVUs } \\
\text { (S) }\end{array}$ & $\begin{array}{l}\text { Average } \\
\text { RVUs: } \\
\text { (NS) }\end{array}$ & $\begin{array}{c}\text { RVU } \\
\text { Difference: } \\
\text { (S)-(NS) }\end{array}$ \\
\hline 1 & 6 & 12 & Rural & $1-A$ & 16 & 8 & 12.51 & 13.21 & -0.7 \\
\hline 2 & 11 & 23 & Rural & $2-A$ & 8 & 4 & 7.87 & 7.27 & 0.6 \\
\hline \multirow{2}{*}{3} & \multirow{2}{*}{4} & \multirow{2}{*}{28} & \multirow{2}{*}{ Rural } & $3-A$ & 16 & 12 & 16.06 & 14.48 & 1.58 \\
\hline & & & & 3-B & 21 & 7 & 13.23 & 12.85 & 0.38 \\
\hline 4 & 7 & 16 & Urban & $4-\mathrm{A}$ & 16 & 8 & 8.6 & 9.16 & -0.56 \\
\hline \multirow{2}{*}{5} & \multirow{2}{*}{18} & \multirow{2}{*}{33} & \multirow{2}{*}{ Rural } & $5-\mathrm{A}$ & 12 & 6 & 10.74 & 13.18 & -2.44 \\
\hline & & & & $5-B$ & 12 & 6 & 13.74 & 13.04 & 0.7 \\
\hline \multirow{3}{*}{6} & \multirow{3}{*}{11} & \multirow{3}{*}{18} & \multirow{3}{*}{ Urban } & $6-A$ & 4 & 2 & 9.3 & 7.38 & 1.92 \\
\hline & & & & $6-B$ & 12 & 6 & 9.73 & 6.86 & 2.87 \\
\hline & & & & $6-C$ & 12 & 6 & 10.25 & 10.58 & -0.33 \\
\hline
\end{tabular}


Table 2: Cumulative Mean of Productivity Measured by RVU and Patients Seen per Half Day With and Without Student $(n=10)$

\begin{tabular}{|c|c|c|c|c|c|}
\hline & Mean & SD & $\begin{array}{c}\text { Mean } \\
\text { Difference }\end{array}$ & $t$ & $P$ \\
\hline RVU & & & \multirow{3}{*}{0.41} & \multirow{3}{*}{0.34} & \multirow{3}{*}{.74} \\
\hline NS & 10.84 & 2.87 & & & \\
\hline$s$ & 11.25 & 2.53 & & & \\
\hline Patie & & & \multirow{3}{*}{0.45} & \multirow{3}{*}{0.56} & \multirow{3}{*}{.58} \\
\hline NS & 8.32 & 1.67 & & & \\
\hline$S$ & 7.87 & 1.91 & & & \\
\hline
\end{tabular}

Abbreviations: RVU, relative value unit; NS, no student (without student); S, student (with student); SD, standard deviation.

\section{Acknowledgments}

The authors are grateful to Tim Evans for providing initial support and study model, Jaime Fitch for administrative support, Amy Pangilinan for data management, and Doug Schaad for analysis.

Financial Support: Support for this study was provided by the Center for Leadership and Innovation in Medical Education (CLIME) Small Grant Program, in the amount of \$5,000 in 2016.

\section{Corresponding Author}

Tomoko Sairenji, MD, MS

E-304, 1959 NE Pacific Street, Seattle, WA 98195-6390. 206-685-7942. Fax: 206-543-9425.

sairenji@uw.edu

\section{Author Affiliations}

Tomoko Sairenji, MD, MS - University of Washington, Department of Family Medicine

Samuel Griffin, MPA - University of Washington, Department of Family Medicine

Misbah Keen, MD, MBI, MPH - University of Washington, Department of Family Medicine

\section{References}

1. Kane C. Updated Data on Physician Practice Arrangements: For the First Time, Fewer Physicians are Owners Than Employees. Chicago, IL: American Medical Association; 2018.

2. Berwick DM, Nolan TW, Whittington J. The triple aim: care, health, and cost. Health Aff (Millwood). 2008;27(3):759-769. https://doi.org/10.1377/hlthaff.27.3.759

3. Association of American Medical Colleges. Recruiting and maintaining U.S. clinical training sites: joint report of the 2013 multi-discipline clerkship/clinical training site survey. 2014; https://members.aamc.org /eweb/upload/13-225WCReport2update.pdf. Accessed Jan 2, 2019.

4. Fields SA, Toffler WL, Bledsoe NM. Impact of the presence of a third-year medical student on gross charges and patient volumes in 22 rural community practices. Acad Med. 1994;69(10)(suppl):S87-S89. https://doi.org /10.1097/00001888-199410000-00052

5. Scott I, Sazegar P. Why community physicians teach students (or not): barriers and opportunities for preceptor recruitment. Med Teach. 2006;28(6):563-565. https://doi.org/10.1080/01421590600627375

6. Latessa R, Beaty N, Colvin G, Landis S, Janes C. Family medicine community preceptors: different from other physician specialties? Fam Med. 2008;40(2):96-101. 
7. McCullough B, Marton GE, Ramnanan CJ. How can clinician-educator training programs be optimized to match clinician motivations and concerns? Adv Med Educ Pract. 2015;6:45-54. https://doi.org/10.2147 /AMEP.S70139

8. Evans TC, Wick KH, Andrilla CHA, Skaggs SA, Burgin T. A Method to Study the Effect of a Physician Assistant Student on Preceptor Productivity. J Physician Assist Educ. 2018;29(4):205-210. https://doi.org/10.1097 /JPA.0000000000000220

Copyright $\odot 2020$ by the Society of Teachers of Family Medicine 